\title{
Late-Stage Immature Neocortical Neurons Reconstruct Interhemispheric Connections and Form Synaptic Contacts with Increased Efficiency in Adult Mouse Cortex Undergoing Targeted Neurodegeneration
}

\author{
Rosemary A. Fricker-Gates, Jennifer J. Shin, Cindy C. Tai, Lisa A. Catapano, and Jeffrey D. Macklis \\ Division of Neuroscience, Children's Hospital, and Department of Neurology and Program in Neuroscience, Harvard \\ Medical School, Boston, Massachusetts 02115
}

In the neocortex, the effectiveness of potential cellular repopulation therapies for diseases involving neuronal loss may depend critically on whether newly incorporated cells can differentiate appropriately into precisely the right kind of neuron, re-establish precise long-distance connections, and reconstruct complex functional circuitry. Here, we test the hypothesis that increased efficiency of connectivity could be achieved if precursors could be more fully differentiated toward desired phenotypes. We compared embryonic neuroblasts and immature murine neurons subregionally dissected from either embryonic day 17 (E17) (Shin et al., 2000) or E19 primary somatosensory (S1) cortex and postnatal day 3 (P3) purified callosal projection neurons (CPNs) with regard to neurotransmitter and receptor phenotype and afferent synapse formation after transplantation into adult mouse $\mathrm{S} 1$ cortex undergoing targeted apoptotic degeneration of layer II/III and V CPNs.

Two weeks after transplantation, neurons from all developmental stages were found dispersed within layers II/III and V, many with morphological features typical of large pyramidal neurons. Retrograde labeling with FluoroGold revealed that $42 \pm 2 \%$ of transplanted E19 immature S1 neurons formed connections with the contralateral S1 cortex by 12 weeks after transplantation, compared with $23 \pm 7 \%$ of $\mathrm{E} 17$ neurons. $\mathrm{A}$ greater percentage of E19-derived neurons received synapses (77 $\pm 1 \%)$ compared with E17-derived neurons (67 $\pm 2 \%)$. Similar percentages of both E17 and E19 donor-derived neurons expressed neurotransmitters and receptors [glutamate, aspartate, GABA, GABA receptor (GABA-R), NMDA-R, AMPA-R, and kainate-R] appropriate for endogenous adult CPNs progressively over a period of 2-12 weeks after transplantation. Although P3 fluorescence-activated cell sortingpurified neurons also expressed these mature phenotypic markers after transplantation, their survival in vivo was poor.

We conclude that later-stage and region-specific immature neurons develop a mature CPN phenotype and make appropriate connections with recipient circuitry with increased efficiency. However, at postnatal stages of development, limitations in survival outweigh this increased efficiency. These results suggest that efforts to direct the differentiation of earlier precursors precisely along specific desired neuronal lineages could potentially make possible the highly efficient reconstruction of complex neocortical and other CNS circuitry.

Key words: neocortex; neural transplantation; migration; integration; connectivity; targeted degeneration; apoptosis; neuronal degeneration; neurotransmitters; receptors; glutamate; aspartate; GABA; kainate-R; NMDA-R; AMPA-R; GABA-R
Neural transplantation offers an approach for cellular repair in the adult mammalian brain. Such repair could circumvent the generally limited capacity of the mature CNS to generate new neurons in response to degeneration or injury. Both rodent and primate studies have shown that immature neurons and their precursors can survive, mature, and extend functional axonal connections after transplantation to areas of neuronal degenera-

Received June 1, 2001; revised March 1, 2002; accepted Feb. 28, 2002.

This research was supported by National Institutes of Health Grants NS41590 and HD28478, by Mental Retardation Research Center Grant HD18655, and by the Alzheimer's Association. R.A.F. was supported by fellowships from the Wills Foundation and the Lefler Center. J.J.S. was supported by a Howard Hughes Medical Institute (HHMI) medical student fellowship, and L.A.C. was supported by an HHMI predoctoral fellowship. We thank Dr. Monte Gates for scientific advice and input throughout the project, Farren Briggs for excellent technical assistance, and Drs. Bartley Mitchell and Sanjay Magavi for advice and help with digital imaging.

Correspondence should be addressed to Jeffrey D. Macklis, Division of Neuroscience, Enders 354, Children's Hospital, 320 Longwood Avenue, Boston, MA 02115. E-mail: jeffrey.macklis@tch.harvard.edu.

R. A. Fricker-Gates's present address: Cardiff School of Biosciences, Cardiff University, Biomedical Sciences Building, Museum Avenue, P.O. Box 911, Cardiff CF10 3US, UK.

Copyright (C) 2002 Society for Neuroscience $\quad 0270-6474 / 02 / 224045-12 \$ 15.00 / 0$ tion, replacing lost neurons both structurally and functionally in the mature CNS (for review, see Dunnett and Björklund, 2000). However, for the replacement of highly specified neuronal populations and optimal reconstruction of complex circuitry, the choice of donor cells may play a crucial role. In the neocortex, the effectiveness of potential transplantation therapy for diseases involving neuronal loss may depend critically on whether donor cells can differentiate appropriately, re-establish precise longdistance connections, and reconstruct functional circuitry.

During the development of specific neuronal populations, neural precursors undergo defined stages of restriction: first, restriction to a neuronal phenotype, and subsequently further refinement of their morphological features and molecular phenotype (e.g., neurotransmitter and receptor expression), to enable their specific role in functional neural processing. Therefore, in selecting the optimal cell types for reconstruction of specific neuronal circuitry, more differentiated donor neuroblasts and later-stage immature neurons, derived from the appropriate regions of the CNS, may have an increased efficiency of appropriate, specific, and fully competent maturation. For example, embryonic day 17 
(E17) neuroblasts transplanted to adult mouse neocortex undergoing apoptotic neuronal degeneration of callosal projection neurons (CPNs) can respond to developmental signal molecules re-expressed in this region, differentiate into projection neurons, and re-form specific distant projections (Macklis, 1993; Sheen and Macklis, 1995; Hernit-Grant and Macklis, 1996; Wang et al., 1998; Shin et al., 2000).

Such results notwithstanding, the relatively limited capacity of survival, migration, integration, and proliferation of immature neurons after transplantation has prompted considerable research into the potential use of less differentiated precursor cells. These early precursors, taken at premigratory stages of development, can make use of available substrates or pathways for migration and integration in the recipient CNS (Gage et al., 1995; Brüstle and McKay, 1996; Lundberg et al., 1997; Snyder et al., 1997; Winkler et al., 1998; Zigova et al., 1998; Fricker et al., 1999; Leavitt et al., 1999). Undifferentiated precursors have other distinct advantages for potential transplantation therapies, including their greater ability for proliferation and greater survival in vivo. Ultimately, neural precursors may provide a relatively unlimited source of neuronal substrates that allow transplantation to be clinically feasible. For example, after transplantation into adult mouse neocortex undergoing targeted apoptosis of projection neurons, early stage neural precursors can respond with many of the same features as more mature neuroblasts, showing neuronal differentiation, afferent synapse formation, and extension of longdistance axonal projections. However, such precursors undergo differentiation and axon projection with decreased efficiency compared with later-stage neuroblasts and immature neurons (Hernit-Grant and Macklis, 1996; Snyder et al., 1997; Sheen et al., 1999; Shin et al., 2000).

For neural or neuronal precursors to be a feasible alternative for transplantation, it will be crucial to understand more fully their intrinsic properties, how these properties change during progressively restricted neuronal differentiation, and how these changes affect the interactions of the cells with external signals in the surrounding environment. Therefore, we tested the hypothesis that increased efficiency of connectivity with the recipient brain could be achieved in vivo if neuroblasts and immature neurons could be more fully and precisely differentiated toward the desired phenotype. We compared populations of increasingly committed immature neocortical neurons, either subregionally dissected neuroblasts or immature CPNs purified from the developing mouse brain, with regard to their ability to undergo precise maturation and establish appropriate long-distance connectivity with the recipient brain after transplantation. In particular, we investigated the ability of the donor neurons to (1) extend specific, long-distance axonal projections to the contralateral cortex in adult mice undergoing apoptotic degeneration of CPNs and (2) differentiate to a mature phenotype, expressing appropriate neurotransmitters and their receptors present in normal adult CPNs. Such analysis directly investigates the ability of transplanted immature neurons at progressively committed stages of differentiation both to re-establish appropriate connectivity within the recipient neocortical circuitry and to potentially function appropriately within that circuitry to replace injured or degenerating neocortical projection neurons.

\section{MATERIALS AND METHODS}

This study is based on data from 71 mice and 26,270 analyzed neurons. Adult male and female C57BJ/6 mice were used according to an institutionally approved protocol. Fifty-nine mice were recipients of dissociated embryonic cells and postnatal neurons into neocortex undergoing targeted neural degeneration. Of these, 12 mice received transplants of E19 S1 immature neurons ( $n=4$ per group examined at each time point), and another 7 mice received postnatal day 3 (P3) fluorescence-activated cell sorting (FACS)-purified CPNs $(n=2-3$ per group examined at each time point). These results were compared with those of 40 mice that received transplants of E17 S1 neuroblasts ( $n=7-8$ per group examined at each time point) (Shin et al., 2000). Twelve mice received transplants of neuroblasts and immature neurons into intact neocortex as agematched controls. These controls underwent FluoroGold (FG; Fluorochrome, Inc., Englewood, NJ) retrograde labeling at 12 weeks.

Induction of targeted neuronal degeneration. Details of chlorin $e_{6}$ injection and exposure to long-wavelength laser light have been described previously (Macklis, 1993; Sheen and Macklis, 1995). For surgery, neonatal 2- to 4-d-old mouse pups were anesthetized by hypothermia. Glass micropipettes with tip diameters of 30-60 $\mu \mathrm{m}$ were used to introduce fluorescein latex nanospheres (LumaFluor, Naples, FL) conjugated with the long-wavelength-absorbing chromophore chlorin $e_{6}$ into the left primary somatosensory cortex (S1), using bregma and the coronal suture as landmarks. Nanospheres were microinjected at depths between $150 \mu \mathrm{m}$ and the surface, at 10 sites spaced evenly throughout S1 cortex, depositing $230 \mathrm{nl}$ total volume to the hemisphere. The pups were subsequently returned to their dams. During the following days, chlorin $e_{6}$-conjugated nanospheres were retrogradely transported across the corpus callosum to the contralateral hemisphere, as described previously (Macklis, 1993; Sheen and Macklis, 1995).

At the age of 6-8 weeks, mice were deeply anesthetized with Avertin $(0.02 \mathrm{ml} / \mathrm{gm})$. A small craniotomy $(\sim 2.5 \times 2.5 \mathrm{~mm})$ was created above the noninjected hemisphere. The somatosensory cortex was subsequently exposed, through intact dura, to light from a continuous-wave $674 \mathrm{~nm}$ near-infrared laser with custom collimating optics. This light exposure initiated the selective degeneration of CPNs, primarily in layer II/III and to a smaller extent in layer $\mathrm{V}$, over the following 1-2 weeks (Fig. 1A) (Macklis, 1993; Madison and Macklis, 1993; Sheen and Macklis, 1994, 1995).

Mice undergoing targeted neuronal degeneration are referred to as "experimental" mice in the text.

Preparation of embryonic cell suspensions. The methods for preparation of subregionally dissected S1 cortical cell suspensions and their transplantation to the adult mouse cortex undergoing targeted neurodegeneration have been described previously (Shin et al., 2000). All transplantations were performed $8 \mathrm{~d}$ after initiation of neuronal death. Timed E19 pregnant C57B6/J mice were terminally anesthetized, and embryos were removed. The developing $\mathrm{S} 1$ region from each cortex was dissected out and placed in dissection medium: buffer supplemented with $0.36 \%$ glucose, $0.8 \mathrm{~mm}$ magnesium kynurenate, $50 \mu \mathrm{m}$ APV, $50 \mathrm{U} / \mathrm{ml}$ penicillin, and $50 \mu \mathrm{g} / \mathrm{ml}$ streptomycin. Tissue pieces underwent enzymatic treatment with $100 \mathrm{U}$ papain for $30 \mathrm{~min}$ at $37^{\circ} \mathrm{C}$, followed by mechanical trituration with a $1 \mathrm{ml}$ plastic Falcon pipette (BD Biosciences, Bedford, MA).

Cell suspensions were labeled with the lipophilic dye PKH 26 red (Sigma, St. Louis, MO) and custom-synthesized latex nanospheres containing rhodamine, which label neurons selectively (Macklis, 1993; Sheen and Macklis, 1995). PKH 26 initially localizes to the membrane, outlining cell somata and processes, and is later concentrated in lysosomes (Honig and Hume, 1989; Ashley et al., 1993). The neuronally incorporated nanospheres are also eventually concentrated in lysosomes and persist in neurons indefinitely (Macklis, 1993; Sheen and Macklis, 1995). Cell suspensions were made at a density of $\sim 5 \times 10^{7}$ cells $/ \mathrm{ml}$ and were kept on ice to optimize cell viability.

Purification of P3 CPNs using FACS. To investigate the ability of increasingly late-stage differentiated CPNs already committed to a callosal neuron phenotype, we took advantage of a recently developed purification, via FACS, of early postnatal callosal neurons that have already formed their contralateral projections (Catapano et al., 2001). In brief, we retrogradely labeled the young neurons via microinjection of fluorescent microspheres directly into their axonal target regions in the contralateral cortex and subsequently purified these neurons by FACS. Purified CPNs were used in preference to mixed P3 cell suspensions to allow investigation of the performance of maximally committed immature callosal neurons, while allowing the earlier-stage E17 and E19 results to be directly comparable with those of previous studies (HernitGrant and Macklis, 1996; Shin et al., 2000). In a series of pilot experiments, we also compared P3 cortical cell suspensions from subregionally dissected S1 cortex, including all cell types. The survival of neurons in 

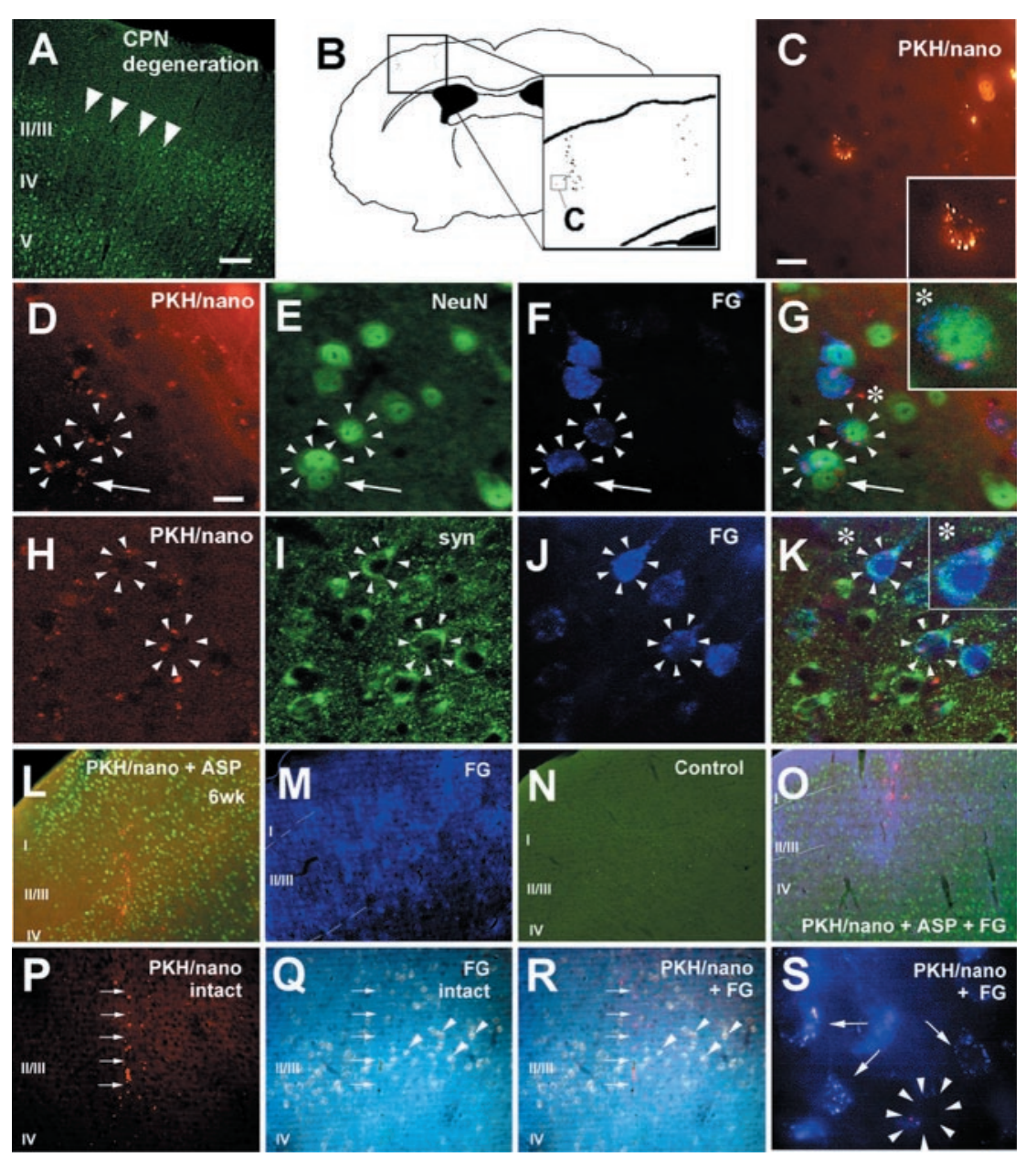

Figure 1. Migration, neuronal differentiation, and synapse formation by E19 immature S1 anlage neurons transplanted to adult $\mathrm{S} 1$ cortex undergoing targeted neuronal degeneration. $A$, Low-magnification image of glutamatergic CPNs in the targeted region of S1 8 weeks after induction of neuronal apoptosis. Arrowheads indicate the region of glutamatergic CPN loss in layer II/III of cortex. $B$, Camera lucida of a coronal section through an experimental adult mouse brain 6 weeks after transplantation. The inset shows two transplantation sites with transplanted E19-derived neurons double-labeled with PKH 26 and rhodamine fluorescent nanospheres. $C$, Area boxed in $B$ shows a PKH 26- and nanospherelabeled E19-derived neuron after migration from the transplantation site (inset at higher magnification). Transplanted neurons developed large, pyramidal cell bodies typical of adult CPNs. $D-G$, High-magnification confocal images of E19-derived neurons 12 weeks after transplantation. Arrowheads indicate PKH 26- and nanosphere-labeled E19-derived neurons $(D)$ that are immunopositive for NeuN $(E)$ and retrogradely labeled with FG from the contralateral S1 cortex $(F)$. $G$, Confocal overlay image of the triple-labeled neurons. Inset shows a triple-labeled neuron (asterisk) at higher magnification. Arrows in $D-G$ indicate a NeuN-positive transplanted neuron that is not labeled with FG. $H-K$, Highmagnification confocal images of E19-derived neurons 12 weeks after transplantation. Arrowheads indicate PKH 26- and nanosphere-labeled E19-derived neurons $(H)$ that colocalize synaptophysin $(I)$ and are retrogradely labeled with $\mathrm{FG}(J)$. $K$, A confocal overlay image of triple-labeled neurons. Inset shows a triple-labeled neuron (asterisk) at higher magnification. At both 6 and 12 weeks, the injection sites were observed spanning layers II/III through $\mathrm{V}(B, L$, and $O)$. $L$, Injection track showing PKH 26- and nanosphere-labeled E19-derived immature neurons (red) 12 weeks after transplantation. $M, \mathrm{FG}$ injections to the contralateral cortex 12 weeks after transplantation led to widespread retrograde labeling throughout layer II/III on the transplanted side, distributed well beyond the regions that contained both

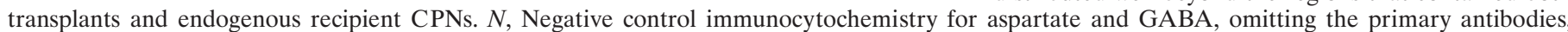

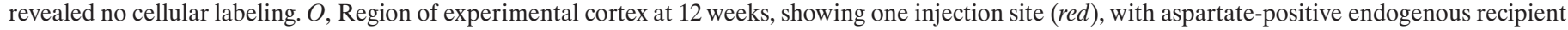

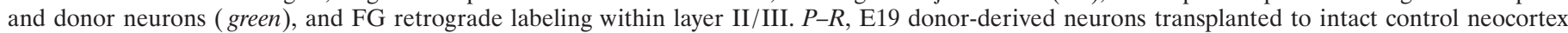

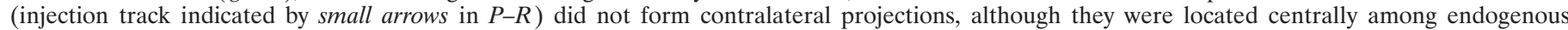

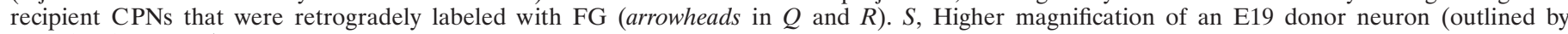

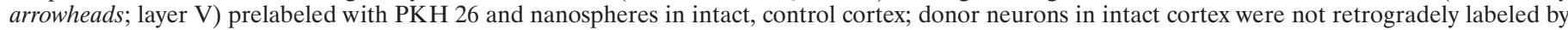

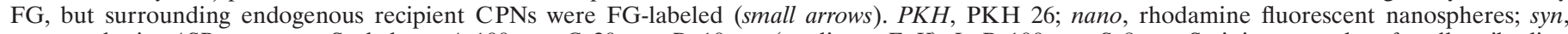

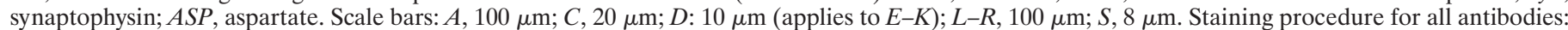

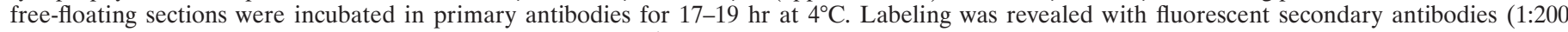

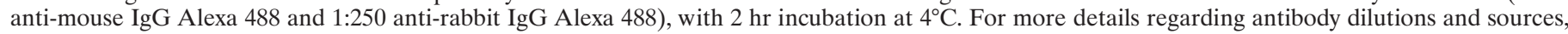
see Materials and Methods.

these mixed S1 cortical dissociations was extremely poor, much poorer than that of the FACS-purified P3 neurons. This compromised survival was potentially attributable to overwhelming glutamate in the medium, which was eliminated by dilution and glutamate blockade in the FACS protocol used. Because of the poor neuronal survival with mixed S1 cortical dissociations, we did not perform further investigations of this type.

To retrogradely label developing CPNs, rhodamine fluorescent latex microspheres (LumaFluor) were injected into the left S1 cortex of 1 -d-old mouse pups according to the protocol outlined above (Catapano et al., 2001). Pups were returned to their dams for $48 \mathrm{hr}$ to allow transport of the microspheres to the contralateral cortex. P3 pups were killed by rapid decapitation, and the $\mathrm{S} 1$ cortex contralateral to the injected side was removed. A single-cell suspension was prepared as for the embryonic tissue. FACS was used to isolate and purify the CPNs, selecting for neurons, both by presence of fluorescence labeling and by large cell soma size ( $>10 \mu \mathrm{m}$ diameter). Purified CPNs were collected in growth medium supplemented with fetal calf serum and kept on ice to optimize their viability during the transplantation procedure. The density of these cell suspensions was lower than that of the mixed cell suspensions $(\sim 1 \times$ $10^{7}$ cells $/ \mathrm{ml}$ ).

Transplantation of cell suspensions. Cell suspensions were transplanted to regions of adult $\mathrm{S} 1$ cortex undergoing targeted neuronal degeneration. Injection tracks spanned layers II/III through V. Micropipettes were used to introduce $50 \mathrm{nl}$ of donor cells at intervals of $50 \mu \mathrm{m}$, from a depth of 500-100 $\mu \mathrm{m}$ (total $300 \mathrm{nl}$ per injection site). Each mouse received six injections, spaced evenly in S1 cortex, with 90,000 E19 cells and 18,000 P3 CPNs injected per mouse. Control transplantations were performed in the same manner into age-matched intact adult mice.

$F G$ injections into transplant recipients. Twelve weeks after transplantation, FG was injected into the contralateral cortex of transplanted mice (both experimental mice that had received chlorin $e_{6}$ and laser exposure and previously intact adult controls) to retrogradely label neurons extending axons to the contralateral hemisphere. A craniotomy $(\sim 2.5 \times 2.5$ $\mathrm{mm}$ ) was created overlying the $\mathrm{S} 1$ cortex contralateral to the transplanted region. Micropipettes were used to deliver $60 \mathrm{nl}$ of FG (a 3\% solution in distilled water) in a grid of 11 sites, placed at intervals of $50 \mu \mathrm{m}$, from a depth of 500-100 $\mu \mathrm{m}$. Four days were allowed for transport to the cell somata in the contralateral hemisphere.

Tissue preparation. At 2, 6, and 12 weeks after transplantation, mice were perfused for immunocytochemical analysis. Mice were terminally anesthetized with Avertin $(0.04 \mathrm{ml} / \mathrm{gm})$ and transcardially perfused with $10 \mathrm{U} / \mathrm{ml}$ heparin in $0.9 \% \mathrm{NaCl}$, followed by $4 \%$ paraformaldehyde $/ 0.4 \%$ glutaraldehyde. Brains were post-fixed in the same solution for 24-41 hr. 
Series of $30 \mu \mathrm{m}$ coronal sections were obtained with a Vibratome (Technical Products International Inc., O’Fallon, MO) and stored in PBS at $4^{\circ} \mathrm{C}$.

Immunocytochemistry. Sets of 10 sections (distributed evenly throughout anterior and posterior regions) were obtained from each mouse for immunocytochemistry. Free-floating sections were incubated with a blocking solution of $5 \%$ bovine serum albumin, $3 \%$ goat serum, and $0.5 \%$ Tween 20 for $2 \mathrm{hr}$. Samples were subsequently incubated with the primary antibody diluted in blocking solution for 17-19 hr. The following primary antibodies were used, at the following dilutions: (1) anti-NeuN IgG (1:100; Chemicon, Temecula, CA; mouse monoclonal); (2) antisynaptophysin IgG $(20 \mu \mathrm{g} / \mathrm{ml}$; Boehringer Mannheim, Indianapolis, IN; mouse monoclonal); (3) anti-glutamate $\operatorname{IgG}$ (1:500; Incstar, Stillwater, MN; mouse monoclonal); (4) anti-aspartate IgG (1:500; Sigma; rabbit polyclonal); (5) anti-GABA IgG (1:500; Incstar; rabbit polyclonal); (6) anti-GABA $_{\mathrm{A}}$ receptor $\beta$ chain IgG1 $(10 \mu \mathrm{g} / \mathrm{ml}$; Boehringer Mannheim; mouse monoclonal); (7) anti-NMDA-R1 IgG2a (1:250; PharMingen, San Diego, CA; mouse monoclonal); (8) anti-glutamate receptor $2 / 3 \mathrm{IgG}$ (AMPA-R) (1:125; Oncogene Sciences, Uniondale, NY; rabbit polyclonal); and (9) anti-glutamate receptor 5, 6, and 7 IgM (KA-R) (1:250; Pharminogen; mouse monoclonal). Samples were also processed with omission of primary antibodies as negative controls (Fig. 1N); there was no nonspecific labeling. Sections were rinsed four times with PBS and incubated with the matching secondary antibody for $2 \mathrm{hr}$. The following secondary antibodies were used at the following dilutions: (1) anti-rabbit IgG Alexa 488 (1:250; Molecular Probes, Leiden, The Netherlands) and (2) anti-mouse IgG Alexa 488 (1:200; Molecular Probes). Sections were subsequently rinsed four times with PBS. All steps were performed at $4^{\circ} \mathrm{C}$. Sections were subsequently mounted and coverslipped with aqueous-based Fluoromount G (Electron Microscopy Sciences, Fort Washington, PA).

Analysis of transplanted neurons. Neuronal counts were performed with either a $40 \times$ or $100 \times$ high-numerical-aperture objective on a Zeiss (Thornwood, NY) microscope equipped with epifluorescence. The following custom excitation and emission filters were used for visualization of fluorescent labeling to eliminate nonspecific fluorescence: (1) excitation, 350-380 nm; barrier, >380 (FG); (2) excitation, 450-490 nm; barrier, 510-540 (Alexa 488, FITC); and (3) excitation, 538-553 nm; barrier, 590-620 (Cy3, rhodamine).

Immunolabeling was considered positive by criteria defined a priori: (1) if the signal was substantially and distinctly above background and (2) if the signal was distinctly above the negative omission-of-primaryantibody controls. Furthermore, the established criteria were that neurotransmitter immunofluorescence was classified as positive only if staining was homogeneous throughout the cytoplasm, and receptor staining was considered positive only if staining was uniform throughout the cell membrane. To be considered double-labeled, morphological features as delineated by FG and fluorescent secondary antibody had to be similar. Rare indeterminately labeled neurons were not included in the analysis.

In individual series of sections (1:10 for sections containing E19 donor immature neurons and 1:5 for sections containing P3 CPNs), donor-derived neurons were identified and their positions relative to the transplantation site were determined. The vertical central line of the narrow injection sites was delineated by use of low-power optics to define the precise placement of each individual micropipette track through the cortex (Fig. 1B,L,O). Only neurons that had migrated $>50 \mu \mathrm{m}$ from the vertical central line of the injection site into layers II/III and V of somatosensory cortex were included in the analysis (Fig. 1C). This criterion was derived from previous studies indicating that the subpopulation of transplanted neuroblasts that actively migrate from the implantation site differentiate into mature neurons and extend axons across the corpus callosum to the contralateral cortex (Macklis, 1993; Sheen and Macklis, 1995; HernitGrant and Macklis, 1996). In addition, for transplantations of E17 neuroblasts and E19 immature neurons, only neurons that had sufficient PKH 26 and nanosphere labeling to delineate $>50 \%$ of the cell circumference were included so as to be certain of the position of the neuronal somata. For P3 purified CPNs, neurons containing $\geq 3$ lysosomes containing fluorescent microspheres were included in the analysis.

Because of the use of microtransplantation of only a few thousand cells per injection site, and therefore the readily quantifiable number of cells per phenotypic marker per animal, all PKH 26- and nanosphere-labeled cells were counted for each series. The mice were recoded so that each investigator remained blinded to the identity of each specimen, and in selected cases, two investigators analyzed the same series of sections to ensure accuracy and reproducibility. Interobserver reproducibility was extremely high.

Image acquisition. Fluorescence micrographs of transplanted immature neurons were obtained with a cooled CCD digital camera (Optronics International, Chelmsford, MA). Confocal images were obtained using a Noran laser confocal system (Noran Instruments, Middleton, W I) on a Nikon (Tokyo, Japan) Diaphot microscope equipped with both an argon/ krypton laser (Midwest Laser Products, Frankfort, IL) and a UV argon laser (Coherent-AMT, Kitchener, Ontario, Canada), with Intervision software (Noran Instruments). For two-dimensional overlays, fluorescence images from rhodamine, fluorescein, and FG excitation and emission spectra for one plane of tissue were combined, and a composite image was prepared.

Statistical analysis. Statistical tests with ANOVA were performed using the statistical package Genstat 5, release 3.2 (Lawes Agricultural trust, Rothamsted, UK). Two-tailed values of $p<0.05$ were considered significant in the ANOVA models. After ANOVA, additional post hoc analyses were performed using the Student-Newman-Keuls $t$ test for more precise identification of significant differences between groups.

\section{RESULTS}

\section{Induction of specific CPN degeneration}

We induced specific apoptotic neuronal degeneration of CPNs in the adult mouse S1 cortex. A substantial loss of the large glutamatergic CPNs occurred specifically in lamina II/III, using glutamate as a marker for mature CPNs. Neuronal apoptosis occurred only within the region exposed to light by the laser optics (Fig. 1A). For clarity in the text, cortex undergoing targeted CPN degeneration is termed "experimental cortex," to distinguish this from "intact" cortex (recipient cortex for "control" transplants).

\section{E19 immature S1 anlage neurons survive, migrate, differentiate into mature neurons, and form synapses with other neurons}

\section{Survival and migration}

E19 S1 anlage neurons transplanted to regions of adult mouse cortex undergoing targeted neurodegeneration (experimental cortex) showed good survival at all time points investigated. Donor-derived neurons were well integrated with morphologically healthy features 12 weeks after transplantation, indicating good long-term survival of the transplanted immature neurons. There was no reduction in the number of E19 donor-derived neurons observed at longer times after transplantation (1182 \pm 656 PKH- and nanosphere-labeled neurons observed per mouse at 2 weeks vs $1466 \pm 331$ neurons per mouse at 12 weeks after transplantation). This is in contrast to previous studies using E17 donor-derived neurons in which the number of donor neurons identified decreased with time after transplantation $(774 \pm 189$ neurons per mouse at 2 weeks, $539 \pm 113$ neurons per mouse at 8 weeks, and $460 \pm 58$ neurons per mouse at 12 weeks after transplantation) (Shin et al., 2000). Therefore, the viability of E19 S1 donor-derived neurons in vivo was not compromised by either the later developmental stage or the cellular dissociation and labeling procedures themselves.

By 2 weeks after transplantation into regions of experimental neocortex, E19 immature neurons migrated specifically to laminas II/III and V (Sheen and Macklis, 1995; Leavitt et al., 1999). Almost all donor-derived neurons were located in layer II/III, with only a few scattered donor-derived neurons located in layer $\mathrm{V}$ (Fig. 1B,C). Although we cannot directly determine from the present data alone whether the migration to layer II/III was specific versus the result of preferential survival of neurons in layer II/III over neurons that migrated to other layers, previous studies have investigated this issue directly and found active and specific migration over a period of 2-3 weeks (Sheen and Macklis, 
1995; Leavitt et al., 1999). In several mice in the present study, donor-derived neuronal profiles were so dense in layer II/III that the region of degeneration appeared to be totally repopulated with donor-derived neurons. Previous studies have found that transplanted E17 neuroblasts undergo a similar pattern of migration (Macklis, 1993; Sheen and Macklis, 1995; Hernit-Grant and Macklis, 1996; Leavitt et al., 1999; Shin et al., 2000).

\section{Neuronal differentiation}

As reported previously with E17 transplanted neuroblasts (Macklis, 1993; Sheen and Macklis, 1995; Hernit-Grant and Macklis, 1996; Shin et al., 2000), many transplanted E19 immature neurons developed morphological features typical of CPNs. This differentiation included large pyramidal cell bodies with apical dendrites and basal axons (Fig. 1C). Two weeks after transplantation, the majority of E19 immature neurons that had migrated $>50 \mu \mathrm{m}$ from the injection site were double-labeled for the neuronal marker MAP2 and had clear apical dendrites present. At 6 and 12 weeks after transplantation, the neuronal marker neuronalspecific nuclear protein $(\mathrm{NeuN})$ was used to identify mature neurons. Twelve weeks after transplantation, $66 \pm 0.5 \%$ of migrated neurons were NeuN-positive (Fig. $1 D-G$ ). However, many additional transplanted neurons that did not demonstrate NeuN labeling had morphological features of large pyramidal neurons. It is likely that these were also mature neurons but did not become labeled with NeuN because of poor penetration of the antibody through the tissue after glutaraldehyde fixation.

After control transplants of the same E19 S1 anlage immature neurons to intact adult mouse cortex that received no laser exposure, substantially fewer E19 immature neurons migrated to layers II/III and V of neocortex. Twelve weeks after transplantation, the number of NeuN-positive neurons present in the control transplants was $\sim 10 \%$ of the number of neurons in transplants to regions of adult mouse cortex undergoing apoptotic neuronal degeneration.

\section{Synapse formation}

To investigate the level to which newly incorporated neurons integrated into cortical circuitry, we assessed the formation of synapses on donor-derived neurons with an antibody against the presynaptic vesicle protein synaptophysin. This presynaptic marker has been used in multiple studies as a marker of synaptic density in cortex as well as other areas of the brain (Saito et al., 1994). We used immunocytochemistry directed against synaptophysin as a marker for synaptic input from other neurons onto the donor-derived neurons.

Many E19 donor-derived neurons transplanted to experimental neocortex had synaptophysin localized to terminals surrounding the cell somata at both 6 and 12 weeks after transplantation (Fig. $1 H-K)$. At 12 weeks after transplantation, $77 \pm 1 \%$ of the E19 donor-derived neurons colocalized synaptophysin. This is significantly more than the $67 \pm 2 \%$ of E17 donor-derived neurons shown previously to colocalize synaptophysin at 12 weeks after transplantation $\left(F_{(6,4)}=19.88 ; p=0.004\right)$. These data provide evidence that neurons formed synaptic inputs to the transplantderived neurons, further supporting their anatomic and functional integration within neocortical circuitry.

\section{E19 donor-derived S1 anlage neurons develop large numbers of long-distance callosal projections}

We quantified the number of transplanted neurons that projected axons to the contralateral cortex by injecting the retrograde label

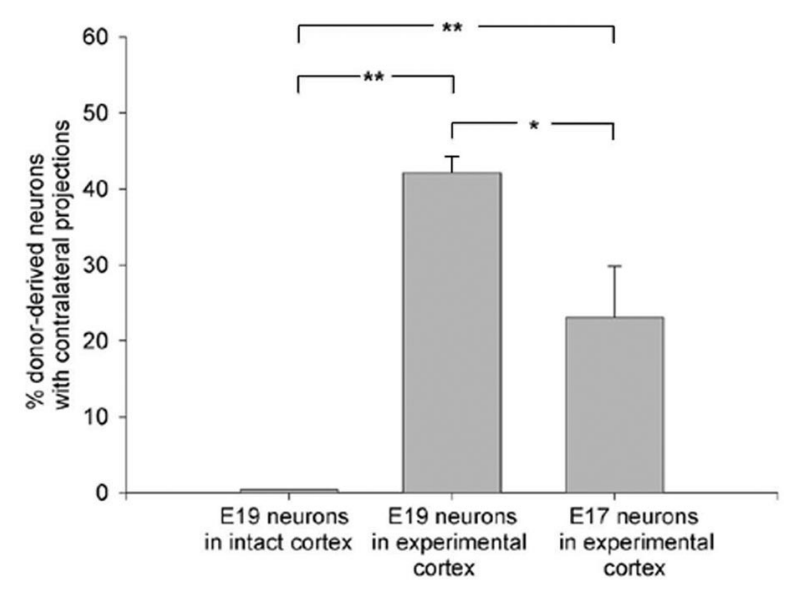

Figure 2. Percentage of E17 and E19 donor-derived neurons that formed long-distance axonal projections to the contralateral S1 cortex, after transplantation into control, intact cortex, or experimental cortex, by retrograde tracing with FG. Asterisks indicate significant differences between groups $\left({ }^{*} p<0.05 ;{ }^{*} p<0.001\right)$.

FG into the contralateral S1 cortical laminas II/III through V at 12 weeks after transplantation. Labeling of CPNs extended throughout layers II/III and V of the contralateral cortex (Fig. $1 M$ ) and corresponded to regions in which both donor-derived neurons and endogenous recipient CPNs were located (Fig. 1O). Of 4689 donor-derived neurons counted in experimental cortex ( $n=4$ mice), $42 \pm 2.2 \%$ were retrogradely labeled with FG, indicating that their axons projected to the appropriate $\mathrm{S} 1$ region of contralateral cortex (Fig. 2). In contrast, no callosal projections were formed by donor-derived neurons from transplants of either E17 or E19 to intact adult cortex by 12 weeks after transplantation ( $0 \%$; 0 of 241 neurons; $n=8$ mice). Therefore, the cellular and molecular signals induced by synchronous apoptosis of adult CPNs created an environment that was permissive and potentially instructive for the regeneration of long-distance projections to appropriate target sites.

Previous results using E17 S1 anlage neuroblasts demonstrated that $23 \pm 6.8 \%$ of E17 donor-derived neurons made specific and appropriate contralateral projections 12 weeks after transplantation to the adult mouse cortex undergoing targeted neurodegeneration (47 of 156 neurons; $n=4$ mice). Statistical comparison of the present results with those previous findings indicates that significantly more transcallosal projections are formed by E19 donor-derived neurons $\left(F_{(9,2)}=3.82 ; p<0.05\right)$ (Fig. 2). Therefore, the later-stage E19 donor-derived neurons are able to regrow a substantial and significantly greater number of longdistance axonal projections to appropriate target regions in the contralateral cortex compared with donor neuroblasts taken at an earlier stage of development. This significant increase in the efficiency of long-distance connectivity may be a result of a greater competence by the later-stage, more developmentally restricted neurons to respond to the environmental signals in the degenerating cortex.

\section{E19 immature S1 anlage neurons develop appropriate neurotransmitter and neurotransmitter receptor expression to enable communication with other neurons}

E19 immature S1 anlage neurons transplanted to experimental adult cortex developed the morphological features, neurotransmitters, and neurotransmitter receptor complement of adult 

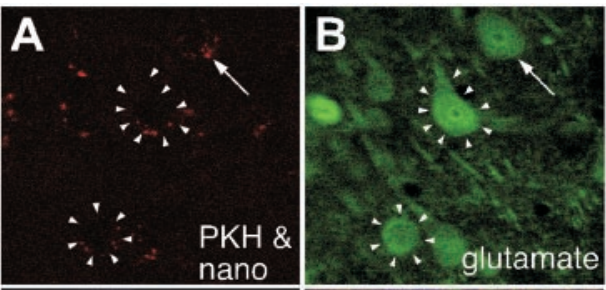

Figure 3. High-magnification confocal images of E19-derived neurons 12 weeks after transplantation expressing each of the neurotransmitters glutamate, aspartate, and GABA. Arrowheads indicate PKH 26- and nanosphere-labeled E19 neurons (red fluorescence in $A$ ) that colocalize glutamate (green fluorescence in $B$ ) and are retrogradely labeled with FG (blue fluorescence in $C$ ) from the contralateral $\mathrm{S} 1$ cortex. $D, \mathrm{~A}$ confocal overlay image of the triple-labeled neurons. Inset shows a triple-labeled neuron (asterisk) at higher magnification. Arrows in $A-D$ indicate a donor-derived neuron that is glutamate immunopositive but FG negative (i.e., that has not projected an axon to reach target sites in the contralateral cortex). E, Line graph comparing the percentage of E19 donor-derived neurons and E17 donor-derived neurons expressing glutamate versus time after transplantation and the percentage of normal adult CPNs that express glutamate. $F$, Confocal overlay image of PKH 26- and nanosphere-labeled E19 donor-derived neurons (red fluorescence), aspartate expression ( green fluorescence), and FG retrograde labeling (blue fluorescence). Arrowheads indicate triplelabeled neurons. $G$, Line graph comparing the percentage of E19 donor-derived neurons and E17 donor-derived neurons expressing aspartate versus time after transplantation and the percentage of normal adult CPNs that express aspartate. $H$, Confocal overlay image of PKH 26- and nanosphere-labeled E19 donor-derived neurons (red fluorescence), GABA expression (green fluorescence), and FG retrograde labeling (blue fluorescence). Arrowheads indicate a triple-labeled neuron. I, Line graph comparing the percentage of E19 donor-derived neurons and E17 donorderived neurons expressing GABA versus time after transplantation and the percentage of normal adult CPNs that express GABA. PKH, PKH 26; nano, rhodamine fluorescent nanospheres. Scale bar (shown in $H): A-D, 20 \mu \mathrm{m} ; F, H, 10 \mu \mathrm{m}$.
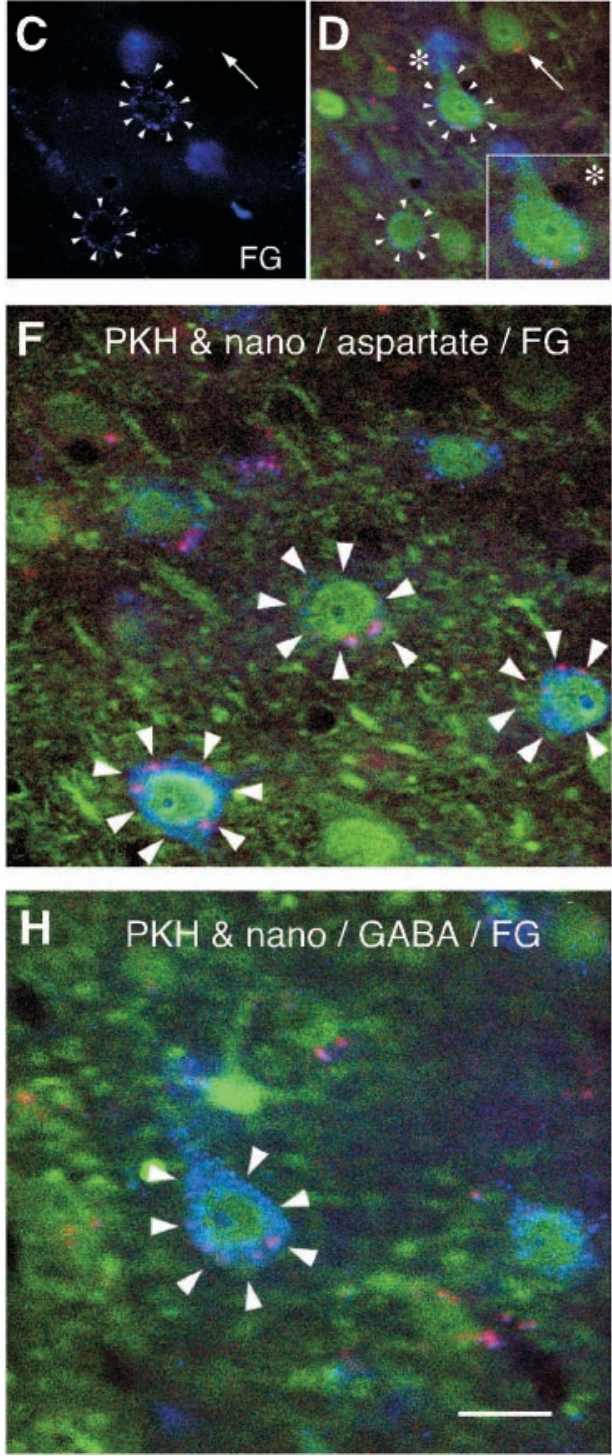

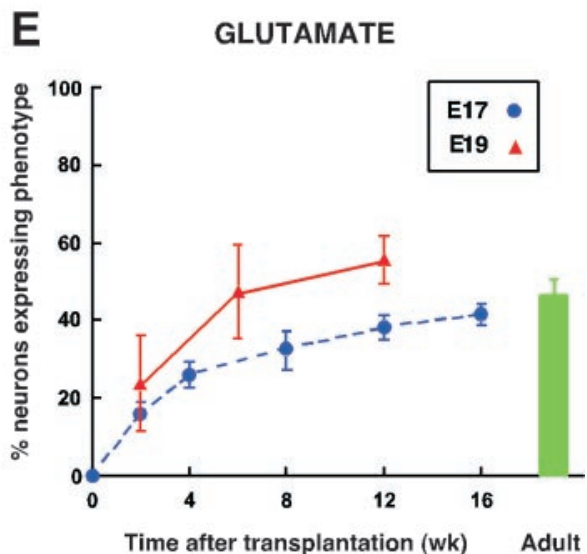

G

ASPARTATE

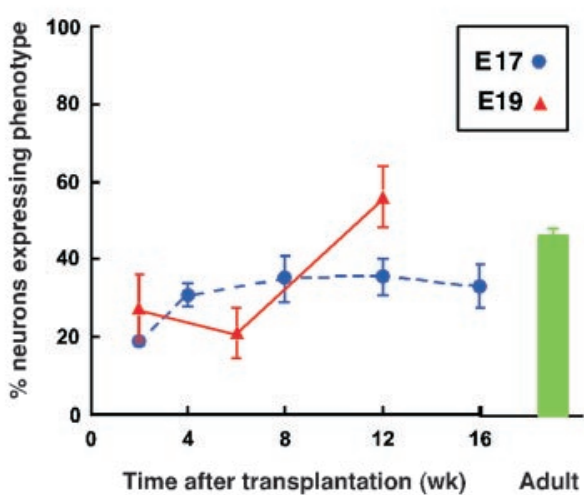

GABA

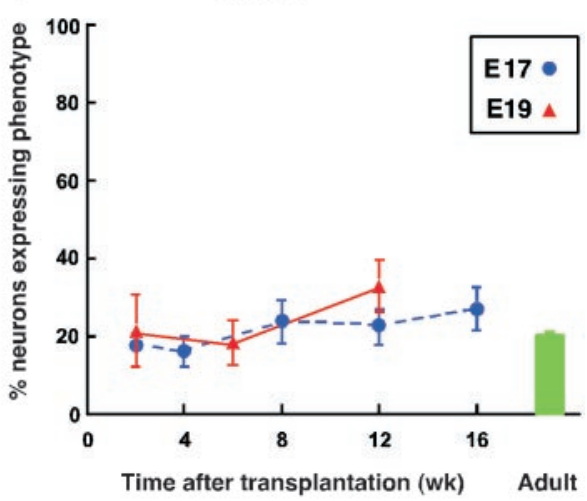

CPNs by 12 weeks after transplantation. These donor-derived neurons expressed the excitatory neurotransmitters glutamate and aspartate in percentages appropriate for adult endogenous CPNs (Fig. 3A-G). These results are similar to those reported previously with E17 neuroblasts (Shin et al., 2000). In addition, appropriate percentages of E19 transplanted neurons expressed NMDA receptors and the non-NMDA receptors kainate-R and AMPA-R, and near-normal percentages expressed GABA-R (Fig. 4). Together, these results indicate that the donor-derived neurons expressed the appropriate complement of cellular machinery not only to transmit efferent synaptic information to other neurons in their circuitry (i.e., appropriate excitatory neurotransmitter expression) but also to receive afferent information from neurons forming synapses with them (via appropriate receptor expression).
The development of neurotransmitter and receptor expression by E19 donor-derived neurons generally followed a time course similar to that seen previously with E17 donor-derived neurons (Shin et al., 2000), with few significant differences between the two groups at any time point after transplantation (Figs. 3E, G,I, $4 B, D, F, H)$. However, differences were observed in the percentages of E19 versus E17 donor-derived neurons expressing the excitatory neurotransmitters glutamate and aspartate when compared 12 weeks after transplantation (Fig. 3E,G). Significantly higher percentages of E19 donor-derived neurons expressed both glutamate and aspartate than did E17 donor-derived neurons (glutamate at 12 weeks, $56 \pm 6 \%$ of E19 vs $39 \pm 3 \%$ of E17derived neurons, $p<0.05$; aspartate at 12 weeks, $56 \pm 8 \%$ of E19 vs $36 \pm 5 \%$ of E17-derived neurons, $p<0.01$ ).

Surprisingly, we found that $\sim 20 \%$ of the donor-derived neu- 

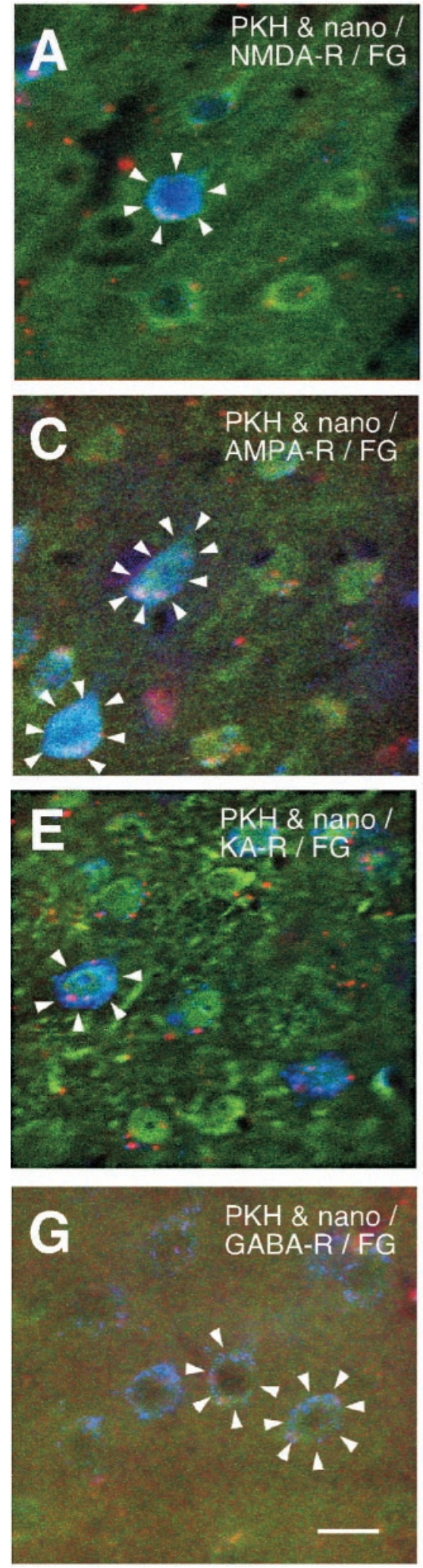
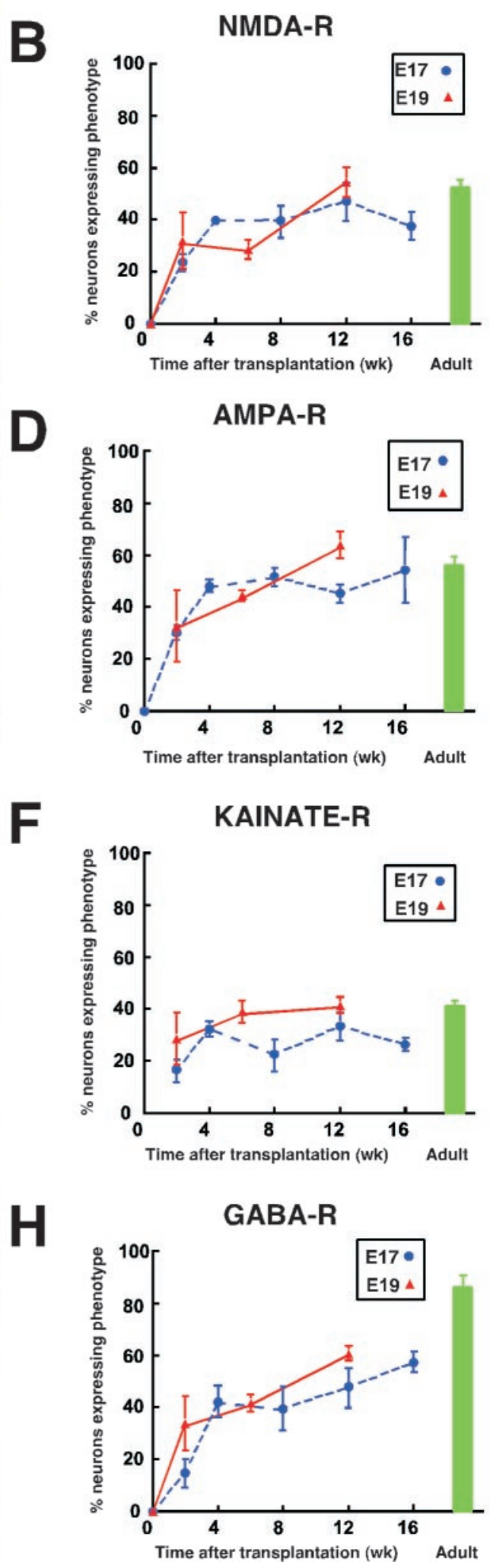

Figure 4. High-magnification confocal images of E19-derived neurons 12 weeks after transplantation, expressing each of the neurotransmitter receptors NMDA-R, AMPA-R, KA-R, and GABA-R. $A, C, E, G$, Confocal images of PKH 26- and nanosphere-labeled E19 donorderived neurons (red fluorescence), receptor expression ( green fluorescence), and FG retrograde labeling from the contralateral $\mathrm{S} 1$ cortex (blue fluorescence). Arrowheads indicate triplelabeled neurons. $B, D, F, H$, Line graphs comparing the percentage of E19 donor-derived neurons and E17 donor-derived neurons expressing each receptor versus time after transplantation and the percentage of normal adult $\mathrm{CPNs}$ that express each receptor. $\mathrm{PKH}$, $\mathrm{PKH}-$ 26; nano, rhodamine fluorescent nanospheres. Scale bar: $G, 15 \mu \mathrm{m}$ (applies to $A, C, E$ ). rons expressed the neurotransmitter GABA (Fig. 3H,I). Control immunocytochemical staining omitting the primary antibody revealed no nonspecific labeling whatsoever, and there was absolutely no GABA staining in the vast majority of neurons when primary antibody was included. Together, these findings indicate that the GABA expression, although unexpected, was specific.
We have previously observed this frequency of GABA expression by pyramidal neurons in layer II/III of cortex in adult mice and by neurons derived from E17 neuroblasts transplanted to the adult mouse cortex undergoing targeted neurodegeneration (Shin et al., 2000). There do not appear to be previous studies reporting such a high percentage of adult CPNs expressing GABA. However, 
the immunofluorescence methods and newer glutaraldehydecross-linked primary antibodies we used may be more sensitive than those used previously. It is well known that a substantial percentage of developing cortical projection neurons express GABA throughout the neonatal period, and it has been thought that they cease expression. It is possible that they downregulate GABA expression but that this lower-level expression is still readily detectable by our methods. From these results, we are unable to predict the role of GABA expression by this low but consistent number of CPNs.

\section{Purified P3 CPNs can survive, migrate, and differentiate into mature CPNs after transplantation in the adult neocortex undergoing targeted neurodegeneration}

To assess whether even further differentiated yet still immature callosal neurons would integrate, differentiate, and form transcallosal connections with even higher efficiency, we investigated whether these already partially differentiated neurons with newly formed callosal projections would survive, migrate, and continue to differentiate into mature CPNs after transplantation to regions of experimental cortex. We isolated and purified postnatal day 3 immature CPNs by FACS. At both 2 and 6 weeks after transplantation, a small number of FACS-purified P3 CPNs were observed immediately adjacent to the injection sites in each recipient mouse. The percentage of surviving neurons was much lower than that observed with either E19 immature neurons or E17 neuroblasts (see Discussion). Despite the poor viability of P3 CPNs in vivo, those neurons that did survive for 6 weeks after transplantation demonstrated the ability to integrate with neocortical circuitry, receiving synapses from other neurons and expressing the appropriate neurotransmitter phenotype of mature CPNs.

\section{Migration}

Because of the poor survival of transplanted P3 CPNs, most of these neurons were located only $50-100 \mu \mathrm{m}$ from the transplantation site. However, occasional FACS-purified P3 CPNs were observed at distances farther from the transplantation site, suggesting that some P3 CPNs maintained the ability to migrate like neuroblasts isolated at E17 and immature neurons isolated at E19.

\section{Phenotypic differentiation and synapse formation}

Transplanted P3 CPNs also developed morphological features typical of adult CPNs by 2 weeks after transplantation, with large pyramidal cell bodies and a primary apical dendrite (Fig. 5A,B). Six weeks after transplantation, FACS-positive neurons were observed that were immunopositive for NeuN (Fig. 5C).

To investigate whether transplanted P3 CPNs acquired the precise phenotype of mature CPNs over time, immunocytochemical analysis was performed for the neurotransmitters glutamate, aspartate, and GABA. Many surviving P3 CPNs expressed glutamate (Fig. 5D), with a small number also expressing aspartate or the inhibitory neurotransmitter GABA. Quantification of neurotransmitter expression was not performed because of the small numbers of surviving P3 CPNs in each experimental cortex after transplantation. By 6 weeks after transplantation, many of the donor-derived P3 CPNs colocalized with the presynaptic marker synaptophysin (Fig. 5E), indicating that these surviving neurons received synaptic input from other neurons. Analysis of longdistance axonal projections was not performed on P3 CPNs
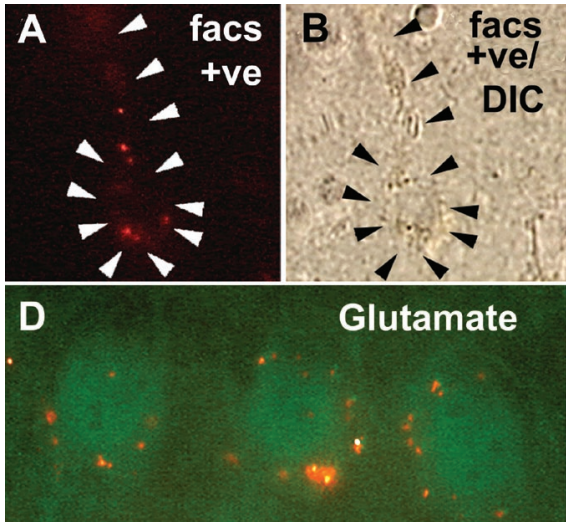

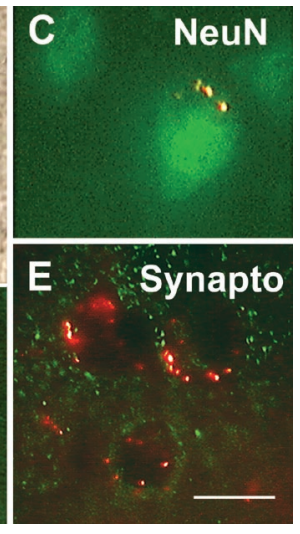

Figure 5. Differentiation of FACS-purified P3 CPNs at 2 and 6 weeks after transplantation. $A$, Donor-derived, FACS-purified CPNs labeled with rhodamine fluorescent microspheres displaying morphological features typical of adult CPNs, with a large pyramidal cell body and prominent apical dendrite. Arrowheads in $A$ and $B$ outline the neuronal soma and apical dendrite. $B$, Same neuron viewed under Nomarski differentia interference contrast $(D I C)$ optics. $C$, Six weeks after transplantation, donor-derived CPNs prelabeled and FACS-purified with rhodamine microspheres (red) expressed the mature neuronal marker NeuN (green). Donor-derived P3 CPNs expressed the excitatory neurotransmitter glutamate (green) $(D)$ and colocalized the presynaptic marker synaptophysin (green) (E). synapto, Synaptophysin; +ve, positive. Scale bar in $E: A-C, E$, $15 \mu \mathrm{m} ; D, 10 \mu \mathrm{m}$.

transplanted to the adult experimental cortex because of poor long-term survival of these donor neurons.

\section{DISCUSSION}

The central finding of this study is that later-stage, progressively restricted neurons from the E19 S1 cortex can differentiate precisely and with increased efficiency compared with earlier-stage donor neurons. E19 S1 anlage neurons transplanted to the adult mouse cortex undergoing targeted CPN degeneration are able to differentiate precisely into a mature CPN phenotype to replace lost neurons, receive synaptic input on an extremely high percentage of the newly incorporated neurons, and extend longdistance axonal projections to appropriate target sites in the contralateral cortex with high efficiency. These later-stage E19 immature neurons demonstrated increased efficiency of reconstruction of long-distance connections compared with earlierstage E17 neuroblasts taken from the equivalent cortical region. E19 neurons also received significantly more synapses from other neurons than did E17 donor-derived neurons. Although FACSpurified postnatal CPNs are also able to differentiate into mature CPNs after transplantation, their survival in vivo is greatly reduced compared with either E19 immature neurons or E17 neuroblasts. Together, these results suggest that in adult neocortex undergoing cell type-specific synchronous neuronal loss, partially developmentally restricted, later-stage immature neurons are able to complete a program of differentiation and circuitry reconstruction with increased efficiency, as long as donor neuron survival is not compromised.

\section{Re-formation of long-distance axonal projections to appropriate target sites}

To the best of our knowledge, this is the first study regarding replacement of complex neuronal circuitry in which such a substantial number (42\%; several hundred per experimental mouse) of transplanted neurons successfully re-formed long-distance axonal projections. In many examples of transplantation to the adult 
cortex using embryonic neurons, either as cell suspensions or as blocks of tissue, investigators have often reported afferent connections to the transplanted cells but no evidence for efferent connections back to the recipient brain (Gonzalez and Sharp, 1987; Gates et al., 2000a). Reports of the extent of efferent connectivity from the graft to recipient tissue have varied widely, from no efferent projections (Gonzalez and Sharp, 1987; Schulz et al., 1993; Grabowski et al., 1995) to sparse or moderate (Bermudez-Rattoni et al., 1987; Isacson et al., 1988; Kelche et al., 1988; Escobar et al., 1989; Sofroniew et al., 1990; Sørensen et al., 1990, 1996; Fernandez-Ruiz et al., 1991; Isacson and Sofroniew, 1992; Schulz et al., 1993) to more extensive innervation of recipient target regions (Gibbs and Cotman, 1987; Guitet et al., 1994; Hernit-Grant and Macklis, 1996). Indeed, in many behavioral studies in which experimental animals did not show improvement after transplantation, investigators have concluded that the lack of functional recovery is most likely attributable to the lack of efferent projections from the transplanted neurons to appropriate recipient target sites.

However, it has been demonstrated previously that embryonic neurons transplanted to a variety of regions in the adult brain are able to extend small numbers of axonal projections successfully and that these projections can be at least partially directed toward appropriate target sites. In the hippocampal formation of mature rodents, "microtransplants" of embryonic tissue send projections into appropriate terminal areas of lesioned entorhinal cortex (Zhou et al., 1985, 1989). Human neurons transplanted in cortex or ventricle (Stromberg et al., 1992) or in the pathway of the lesioned nigrostriatal system in adult rats (Wictorin et al., 1992) can extend axons toward nigral targets; these axons can travel along white-matter tracts of the median forebrain bundle and internal capsule for distances of up to $20 \mathrm{~mm}$, avoiding areas that are not normal targets for nigral neurons. Similarly, transplanted embryonic neurons from either rodent or porcine striatum (Wictorin et al., 1989; Deacon et al., 1994) or human progenitor cells (Fricker et al., 1999) can extend axons specifically toward their targets, the globus pallidus and substantia nigra, using whitematter tracts of the internal capsule and median forebrain bundle.

In previous studies from our laboratory transplanting E17 embryonic neuroblasts to the adult S1 cortex undergoing synchronous CPN degeneration, $21 \pm 5 \%$ (Hernit-Grant and Macklis, 1996 ) or $23 \pm 6.8 \%$ (Shin et al., 2000) of donor-derived neurons projected axons specifically to the appropriate contralateral S1 cortex, with no projections observed to three alternative, normal targets of other subpopulations of neurons located in S1 (ipsilateral thalamus, S2 cortex, and motor cortex) (Hernit-Grant and Macklis, 1996). These results have been confirmed recently (Shin et al., 2000). The studies reported here on the survival of E19 immature neurons and P3 purified CPNs were performed in parallel with the previously reported studies with E17 neuroblasts (Shin et al., 2000), using identical techniques, and therefore can be compared directly. The present results confirm and extend these previous findings, demonstrating that embryonic S1 anlage neurons transplanted at a later stage in their development (E19) can re-form precise connections to contralateral targets with highly increased efficiency compared with younger E17 neuroblasts.

The mechanisms that guide donor-derived neurons to develop specific and substantial numbers of long-distance axonal projections are currently not well identified. Clearly, both intrinsic and extrinsic factors are likely to play a role in this efficient maturation and reconnection of complex circuitry (Lanier et al., 1999;
Gates et al., 2000b). At the time of dissociation, E19 immature S1 CPNs have already formed initial axonal projections, with most CPN axons having reached the midline or contralateral cortex. Therefore, at the time that we removed these immature neurons for transplantation, axons of those destined to become CPNs were already actively developing and seeking appropriate pathways for extension to target sites. E17 neuroblasts are at an earlier stage of development and are just beginning the process of axon formation. The significantly greater number of contralaterally projecting axons formed from the later-stage E19 immature neurons compared with E17 neuroblasts (approximately twofold more) suggests that cell-intrinsic developmental pathways of projection neuron development that were already under way were able to continue after transplantation of these neurons in vivo in the adult brain undergoing targeted neurodegeneration. The younger E17 neuroblasts either were not as far along their developmental pathway to be able to continue this intrinsic developmental program as efficiently or, alternatively, did not respond to external signals as efficiently to enable this later developmental process of axonal elongation. Other transplantation experiments suggest that specification of corticocortical connections by cerebral tissue grafts is also linked to the timing of neurogenesis, with postmitotic neurons increasingly adopting a pattern of connectivity consistent with their having already initiated a specific differentiation program (Barbe and Levitt, 1995).

An alternative explanation is that the younger E17 neuroblasts may require $>12$ weeks after transplantation to develop full axonal projections because they were dissociated at an earlier stage of development. If this were the case, at later survival times, E17 donor-derived neurons would be predicted to show increased numbers of axonal projections similar to those seen with E19 neurons. This is unlikely, however, because data on the development of neurotransmitter and receptor phenotype by E17 neuroblasts parallel those of the E19 immature neurons within a few days. Furthermore, the percentage of transplanted E17 neuroblasts expressing most neurotransmitters and receptors reaches that seen in the adult CPNs by 4-8 weeks after transplantation, indicating that an adult CPN phenotype is already present (Shin et al., 2000).

It is likely that there are extracellular signals that control and permit the mature differentiation and axon elongation of the transplanted embryonic neurons. In mice that received transplants of either E17 neuroblasts or E19 S1 immature neurons into intact cortex, no contralateral projections were observed, indicating that the environment produced by synchronous apoptotic degeneration of CPNs facilitated the projection of axons from donor-derived neurons. Previous experiments have shown that during synchronous, targeted degeneration of CPNs in the adult mouse cortex, there is local upregulation of a specific set of both known developmental genes and novel genes, now under investigation (Wang et al., 1998; L. Li, Arlotta, T. Deuel, T. Chae, J. D. Macklis, unpublished observations). The genes for brain-derived neurotrophic factor, neurotrophin $4 / 5$, and neurotrophin 3 are dramatically upregulated by adjacent synaptically connected interneurons (Wang et al., 1998). Neurotrophins are known to regulate both the neurotransmitter and receptor phenotype of neurons (Widmer and Hefti, 1994; Thoenen, 1995; Takei et al., 1997; Y. X. Li et al., 1998; Pellegri et al., 1998; Sala et al., 1998), axon elongation (LeRoux and Reh, 1994; Segal et al., 1995; Bosco and Linden, 1999), and synapse formation (Wang and Poo, 1997; Vicario-Abejon et al., 1998). Therefore, it is likely that both neurotrophins and as yet unidentified factors may play a role in 
stimulating and/or supporting the projection of axons of donorderived neurons to distant denervated target sites.

\section{Development of a mature CPN phenotype}

Both E19 immature S1 anlage neurons and P3 purified CPNs developed the phenotype of mature CPNs after transplantation to the adult experimental cortex. With E19 donor-derived neurons, the developmental expression of both neurotransmitters and receptors paralleled that seen with previous studies using E17 neuroblasts from the same region of S1 cortex (Shin et al., 2000). Two exceptions to this parallel differentiation were the higher percentages of E19 donor-derived neurons expressing the excitatory neurotransmitters glutamate and aspartate 12 weeks after transplantation. Therefore, these later-stage developing CPNs were able to differentiate to a highly specified and appropriate phenotype to replace adult CPNs induced to degenerate by targeted apoptosis, completing a complex program of projection neuron differentiation, even after being placed in a novel environment in vivo.

The increased number of E19 transplanted neurons that expressed glutamate and aspartate compared with their E17 counterparts may be attributable to the intrinsic state of the immature neurons themselves. Developmental programs for the expression of each particular cortical neurotransmitter phenotype may be both separate and activated in a time-dependent manner (for review, see Levitt et al., 1993). It is possible that the progression of expression of the neurotransmitters and neurotransmitter receptors investigated here reflects their normal developmental order of expression. The transplanted immature neurons may have already initiated a program of progressive gene expression by the time of transplantation. The E17 neuroblasts dissociated for transplantation may be less well equipped to respond to the environmental signals present to initiate intrinsic programs required for the development of expression of specific neurotransmitters or receptors than when taken at the slightly later stage of E19. Indeed, it has been suggested previously that during development, distinct classes of cortical projection neurons are already formed before neuronal migration from the neuroepithelium to their specific lamina within the cortex (Koester and O'Leary, 1993). In that case, the local environment in the experimental mice might be especially supportive of the survival of these later-stage neurons during their differentiation.

\section{Synapse formation}

The colocalization of synaptophysin to the donor-derived E19 neurons and P3 CPNs indicates the development of afferent synaptic contacts onto the transplanted neurons. Synaptic contacts potentially derive from endogenous local interneurons or contralateral CPNs or from other donor-derived neurons. The significantly greater number of synapses formed on the later-stage E19 immature neurons again suggests that intrinsic developmental programs that were already under way at the time of transplantation were able to continue after transplantation of the neurons in vivo in the adult brain undergoing targeted neurodegeneration. It is known, for example, that synapse formation occurs at the same time as clustering of postsynaptic receptors preferentially at synaptic sites (J. H. Li et al., 1998). It is not clear whether neurotransmitter receptor expression precedes synaptogenesis or, alternatively, is a consequence of synapse formation on the postmitotic neuron itself (Poulter and Brown, 1999). Whichever is the case, the developmental programs already under way in the later-stage E19 neurons most likely increased their efficiency both to develop a fully mature phenotype (as described above) and to form both afferent and efferent connections with other neurons compared with less developed, E17 neuroblasts.

The presence of the receptors GABA-R, NMDA-R, AMPA-R, and KA-R on donor-derived neurons suggests that these neurons have the appropriate postsynaptic machinery to allow functional synaptic contacts (i.e., the ability to receive information from other neurons). The measurement of electrophysiological activity in donor-derived neurons or the activation of downstream molecules in signaling pathways will indicate whether the synapses formed on transplanted neurons are able to function normally. This awaits additional investigation.

\section{Evidence for complex circuit reconstruction}

The reconstruction of lost neuronal circuitry may be an important prerequisite for the restoration of neural function in regions of the adult brain that have undergone neurodegeneration. The ability of E19 donor-derived neurons to develop a mature CPN phenotype with high fidelity, to receive synapses from other neurons, and to produce a substantial number of appropriate long-distance callosal projections to the contralateral cortex provides compelling evidence that these immature neurons can effectively reconstruct the complex cortical circuitry lost by the degeneration of adult CPNs. The expression of the excitatory neurotransmitters glutamate and aspartate by appropriate numbers of transplanted E19 neurons suggest the competence of the neurons to transmit appropriate, excitatory information to the contralateral cortex. The expression of appropriate neurotransmitter receptors in appropriate numbers indicates that transplanted E19 immature neurons are competent to receive information from other neurons. Together, the presence of a substantial number of axonal projections to appropriate target regions from these later-stage E19 immature neurons and the substantial number of synapses formed from other neurons onto the transplanted neurons suggest that the complex cortical system of the corpus callosum has been at least partially rewired, both accurately and efficiently.

\section{The effects of developmental stage on the survival of donor-derived neurons in vivo}

The percentage of surviving donor-derived P3 CPNs after transplantation was much lower than that observed with either E19 donor-derived neurons or E17 donor-derived neurons. This low level of neuronal survival is probably a result of a number of different factors. These postnatal CPNs are extremely sensitive to both physical trauma, such as axotomy, and glutamate toxicity. Although such purified P3 CPNs survive well in culture after isolation and FACS purification, these neurons require protection from exposure to substantial glutamate via glutamate depletion of the medium and glutamate blockade, specific growth factor support, and stable attachment to a substrate (Catapano et al., 2001). Maintaining P3 CPNs as a single-cell suspension led to a rapid decrease in viability over the time required for transplantation into multiple recipients (from $75 \%$ to $35 \%$ over a period of $2 \mathrm{hr}$ ). Stress to these P3 CPNs may have been further increased by their low density, both in the dissociated cell suspension and once transplanted into the adult neocortex. This low density most likely reduced the ability of neighboring neurons to provide trophic support. In addition, the absence of glia from the transplantation suspension may have removed an important source of growth factor and other trophic support to these immature but fragile P3 CPNs. 


\section{Choice of donor cells for the replacement of degenerating neurons in vivo}

The data reported here indicate that transplanted later-stage, progressively restricted neurons isolated from the appropriate region of developing S1 cortex can efficiently re-form afferent and efferent connections with recipient brain circuitry, as long as neuronal survival is not compromised. Highly efficient neuronal circuit reconstruction, and hence functional recovery, may be most successful with transplanted neurons or precursors that are most competent to complete specific, complex developmental programs accurately and with high fidelity in vivo. The use of more differentiated but still immature neurons for in vivo neuronal replacement is complicated by issues of tissue isolation, neuron viability, and ease of manipulation. However, our results and those of others argue strongly that immature neurons at later stages of development are able to complete their developmental program with increased efficiency compared with earlier-stage immature neurons. It may be important to reconcile these two issues by guiding more flexible, less differentiated neurons or precursors along highly specific differentiation paths of specific desired neuronal lineages. Investigation of cellular and molecular controls over precise development restriction and maturation (Catapano et al., 2001) may allow isolation and directed manipulation of isolated precursors or stem cells either in vitro or in vivo or their manipulation in situ (Magavi et al., 2000; Scharff et al., 2000) toward specific and efficient replacement of complex neuronal circuitry in the adult brain.

\section{REFERENCES}

Ashley DM, Bol SJ, Waugh C, Kannourakis G (1993) A novel approach to the measurement of different in vitro leukaemic cell growth parameters. Leuk Res 17:873-882.

Barbe MF, Levitt P (1995) Age-dependent specification of the corticocortical connections of cerebral grafts. J Neurosci 15:1819-1834.

Bermudez-Rattoni F, Fernandez J, Sanchez MA, Aguilar-Roblero R, Drucker-Colin R (1987) Fetal brain transplants induce recuperation of taste aversion learning. Brain Res 416:147-152.

Bosco A, Linden R (1999) BDNF and NT-4 differentially modulate neurite outgrowth in developing retinal ganglion cells. J Neurosci Res $57: 759-769$.

Brüstle O, McKay RDG (1996) Neuronal progenitors as tools for cell replacement in the nervous system. Curr Opin Neurobiol 6:688-695.

Catapano LA, Arnold MW, Perez FA, Macklis JD (2001) Specific neurotrophic factors support the survival of cortical projection neurons at distinct stages of development. J Neurosci 21:8863-8872.

Deacon TW, Pakzaban P, Burns LH, Dinsmore J, Isacson O (1994) Cytoarchitectonic development, axon-glia relationships, and long distance axon growth of porcine striatal xenografts in rats. Exp Neurol 130:151-167.

Dunnett SB, Björklund A (2000) Functional transplantation II: novel cell therapies for CNS disorders. In: Progress in brain research, Vol 127 (Dunnett SB, Björkland A, eds), pp 1-559. Oxford: Elsevier Science.

Escobar M, Fernandez J, Guevara-Aguilar R, Bermudez-Rattoni F (1989) Fetal brain grafts induce recovery of learning deficits and connectivity in rats with gustatory neocortex lesion. Brain Res 478:368-374

Fernandez-Ruiz J, Escobar ML, Pina AL, Diaz-Cintra S, CintraMcGlone FL, Bermudez-Rattoni F (1991) Time-dependent recovery of taste aversion learning by fetal brain transplants in gustatory neocortex-lesioned rats. Behav Neural Biol 55:179-193.

Fricker RA, Carpenter MK, Winkler C, Greco C, Gates MA, Bjorklund A (1999) Site-specific migration and neuronal differentiation of human neural progenitor cells after transplantation in the adult rat brain. J Neurosci 19:5990-6005.

Gage FH, Coates PW, Palmer TD, Kuhn HG, Fisher LJ, Suhonen JO, Peterson DA, Suhr ST, Ray J (1995) Survival and differentiation of adult neural progenitor cells transplanted to the adult brain. Proc Natl Acad Sci USA 92:11879-11883.

Gates MA, Fricker-Gates RA, Macklis JD (2000a) Reconstruction of cortical circuitry. Prog Brain Res 127:115-156.

Gates MA, Tai CC, Macklis JD (2000b) Abnormal differentiation and process elongation by TrkB deficient neocortical neurons in vitro and in vivo. Neuroscience 98:437-447.
Gibbs RB, Cotman CW (1987) Factors affecting survival and outgrowth from transplants of entorhinal cortex. Neuroscience 21:699-706.

Gonzalez MF, Sharp FR (1987) Fetal frontal cortex transplanted to injured motor/sensory cortex of adult rats: reciprocal connections with host thalamus demonstrated with WGA-HRP. Exp Neurol 99:154-165.

Grabowski M, Johansson BB, Brundin P (1995) Neocortical grafts placed in the infarcted brain of adult rats: few or no efferent fibers grow from transplant to host. Exp Neurol 134:273-276.

Guitet J, Garnier C, Ebrahimi-Gaillard A, Roger M (1994) Efferents of frontal or occipital cortex grafted into adult rat's motor cortex. Neurosci Lett 180:265-268.

Hernit-Grant CS, Macklis JD (1996) Embryonic neurons transplanted to regions of targeted photolytic cell death in adult mouse somatosensory cortex re-form specific callosal projections. Exp Neurol 139:131-142.

Honig MG, Hume RI (1989) Carbocyanine dyes. Novel markers for labelling neurons. Trends Neurosci 12:333-335.

Isacson O, Sofroniew MV (1992) Neuronal loss or replacement in the injured adult cerebral neocortex induces extensive remodeling of intrinsic and afferent neural system. Exp Neurol 117:151-175.

Isacson O, Wictorin K, Fischer W, Sofroniew MV, Björklund A (1988) Fetal cortical cell suspension grafts to the excitotoxically lesioned neocortex: anatomical and neurochemical studies of trophic interactions. Prog Brain Res 78:13-26.

Kelche C, Dalrymple-Alford JC, Will B (1988) Housing conditions modulate the effects of intracerebral grafts in rats with brain lesions. Behav Brain Res 28:287-295.

Koester SE, O'Leary DD (1993) Connectional distinction between callosal and subcortically projecting cortical neurons is determined prior to axon extension. Dev Biol 160:1-14.

Lanier LN, Gates MA, Witke W, Menzies AS, Wehman AM, Macklis JD, Kwiatowski D, Soriano P, Gertler FB (1999) Mena is required for neurulation and commissure formation. Neuron 22:313-325.

Leavitt BR, Hernit-Grant CS, Macklis JD (1999) Mature astrocytes transform into transitional radial glia within adult mouse neocortex that supports directed migration of transplanted immature neurons. Exp Neurol 157:43-57.

LeRoux PD, Reh TA (1994) Regional differences in glial-derived factors that promote dendritic outgrowth from mouse cortical neurons in vitro. J Neurosci 14:4639-4655.

Levitt P, Ferri RT, Barbe MF (1993) Progressive acquisition of cortical phenotypes as a mechanism for specifying the developing cerebral cortex. Perspect Dev Neurobiol 1:65-74.

Li JH, Wang YH, Wolfe BB, Kreuger KE, Corsi L, Stocca G, Vicini S (1998) Developmental changes in localization of NMDA receptor subunits in primary cultures of cortical neurons. Eur J Neurosci 10:1704-1715.

Li YX, Zhang Y, Lester HA, Schuman EM, Davidson N (1998) Enhancement of neurotransmitter release induced by brain-derived neurotrophic factor in cultured hippocampal neurons. J Neurosci 18:10231-10240.

Lundberg C, Martinez-Serrano A, Cattaneo E, McKay RDG, Björklund A (1997) Survival, integration and differentiation of neural stem cell lines after transplantation to the adult rat striatum. Exp Neurol 145:342-360.

Macklis JD (1993) Transplanted neocortical neurons migrate selectively into regions of neuronal degeneration produced by chromophore targeted laser photolysis. J Neurosci 13:3848-3863.

Madison R, Macklis JD (1993) Noninvasively induced degeneration of neocortical pyramidal neurons in vivo: selective targeting by laser activation of retrogradely transported photolytic chromophore. Exp Neurol 121:153-159.

Magavi SS, Leavitt BR, Macklis JD (2000) Induction of neurogenesis in the neocortex of adult mice. Nature 405:951-955.

Pellegri G, Magistretti PJ, Martin JL (1998) VIP and PACAP potentiate the action of glutamate on BDNF expression in mouse cortical neurones. Eur J Neurosci 10:272-280.

Poulter MO, Brown LA (1999) Transient expression of GABA $_{\mathrm{A}}$ receptor subunit mRNAs in the cellular processes of cultured cortical neurons and glia. Brain Res Mol Brain Res 69:44-52.

Saito S, Kobayashi S, Ohashi Y, Igarashi M, Kormiya Y, Ando S (1994) Decreased synaptic density in aged brains and its prevention by rearing under enriched environment as revealed by synaptophysin contents. J Neurosci Res 39:57-62.

Sala R, Viegi A, Rossi FM, Pizzorusso T, Bonanno G, Raiteri M, Maffei L (1998) Nerve growth factor and brain-derived neurotrophic factor increase neurotransmitter release in the rat visual cortex. Eur J Neurosci 10:2185-2191.

Scharff C, Kirn J, Grossman M, Macklis JD, Nottebohm F (2000) Targeted neuronal death affects neuronal replacement and vocal behavior in adult songbirds. Neuron 25:481-492.

Schulz MK, Hogan TP, Castro AJ (1993) Connectivity of fetal neocortical block transplants in the excitotoxically ablated cortex of adult rats. Exp Brain Res 96:480-486.

Segal RA, Pomeroy SL, Stiles CD (1995) Axonal growth and fascicula- 
tion linked to differential expression of BDNF and NT3 receptors in developing cerebellar granule cells. J Neurosci 7:4970-4981.

Sheen VL, Macklis JD (1994) Apoptotic mechanisms in targeted neuronal cell death by chromophore activated photolysis. Exp Neurol 130:67-81.

Sheen VL, Macklis JD (1995) Targeted neocortical cell death in adult mice guides migration and differentiation of transplanted embryonic neurons. J Neurosci 15:8378-8392.

Sheen VL, Arnold MW, Wang Y, Macklis JD (1999) Neural precursor differentiation following transplantation into neocortex is dependent on intrinsic developmental state and receptor competence.

Shin JJ, Fricker-Gates RA, Perez FA, Leavitt BR, Zurakowski D, Macklis JD (2000) Transplanted neuroblasts differentiate appropriately into projection neurons with correct neurotransmitter and receptor phenotype in neocortex undergoing targeted projection neuron degeneration. J Neurosci 20:7404-7416.

Snyder EY, Yoon C, Flax JD, Macklis JD (1997) Multipotent neural precursors can differentiate toward replacement of neurons undergoing targeted apoptotic degeneration in adult mouse neocortex. Proc Natl Acad Sci USA 94:11663-11668.

Sofroniew MV, Dunnett SB, Isacson O (1990) Remodelling of intrinsic and afferent systems in neocortex with cortical transplants. Prog Brain Res 82:313-319.

Sørensen JC, Wanner-Olsen H, Tøder N, Danielsen E, Castro AJ, Zimmer J (1990) Axotomized, adult basal forebrain neurons can innervate fetal frontal cortex grafts: a double fluorescent tracer study in the rat. Exp Brain Res 92:299-309.

Sørensen JC, Grabowski M, Zimmer J, Johansson BB (1996) Fetal neocortical tissue blocks implanted in brain infarcts of adult rats interconnect with the host brain. Exp Neurol 138:227-235.

Stromberg I, Bygdeman M, Almqvist P (1992) Target specific outgrowth from human mesencephalic tissue grafted to cortex or ventricle of immunosuppressed rats. J Comp Neurol 315:445-456.

Takei N, Sasaoka K, Inoue K, Takahashi M, Endo Y, Hatanaka H (1997) Brain-derived neurotrophic factor increases the stimulation-evoked release of glutamate and the levels of exocytosis-associated proteins in cultured cortical neurons from embryonic rats. J Neurochem $68: 370-375$.
Thoenen H (1995) Neurotrophins and neuronal plasticity. Science 270:593-598.

Vicario-Abejon C, Collin C, McKay RD, Segal M (1998) Neurotrophins induce formation of functional excitatory and inhibitory synapses between cultured hippocampal neurons. J Neurosci 18:7256-7271.

Wang X, Poo M (1997) Potentiation of developing synapses by postsynaptic release of neurotrophin-4. Neuron 19:825-835.

Wang Y, Sheen VL, Macklis JD (1998) Cortical interneurons upregulate neurotrophins in vivo in response to targeted apoptotic degeneration of neighboring pyramidal neurons. Exp Neurol 154:389-402.

Wictorin K, Simerly RB, Isacson I, Swanson LW, Björklund A (1989) Connectivity of striatal grafts implanted into ibotenic acid lesioned striatum. III. Efferent projecting graft neurons and the relation to host afferents within grafts. Neuroscience 30:313-330.

Wictorin K, Brundin P, Sauer H, Lindvall O, Björklund A (1992) Long distance directed axonal growth from human dopaminergic mesencephalic neuroblasts implanted along the nigrostriatal pathway in 6-hydroxydopamine lesioned adult rats. J Comp Neurol 323:475-494.

Widmer HR, Hefti F (1994) Stimulation of GABAergic neuron differentiation by NT-4/5 in cultures of rat cerebral cortex. Brain Res Dev Brain Res 80:279-284.

Winkler C, Fricker RA, Gates MA, Olsson M, Hammang JP, Carpenter MK, Björklund A (1998) Incorporation and glial differentiation of mouse EGF-responsive neural progenitor cells after transplantation into the embryonic rat brain. Mol Cell Neurosci 11:99-116.

Zhou CF, Raisman G, Morris RJ (1985) Specific patterns of fibre outgrowth from transplants to host mice hippocampi, shown immunohistochemically by the use of allelic form of Thy-1. Neuroscience 16:819-833.

Zhou CF, Li Y, Raisman G (1989) Embryonic entorhinal transplants project selectively to the deafferented entorhinal zone of adult mouse hippocampi, as demonstrated by the use of Thy-1 allelic immunohistochemistry. I. Effect of timing of transplantation in relation to deafferentation. Neuroscience 32:349-362.

Zigova T, Pencea V, Betarbet R, Wiegand SJ, Alexander C, Bakay RA, Luskin MB (1998) Neuronal progenitor cells of the subventricular zone differentiate and disperse following transplantation into the adult rat striatum. Cell Transplant 7:137-156. 